\title{
Teaching Reform of Computer Network Course for Engineering Applications
}

\author{
Leian Liu ${ }^{1, a}$, Ying Zou ${ }^{1, ~ b, ~ *, ~ Y u q i a n g ~ S h i ~}{ }^{1, c}$, and Ling Yang ${ }^{1, d}$ \\ ${ }^{1}$ College of Information Science and Technology, Zhongkai University of Agriculture and \\ Engineering, Guangzhou, China

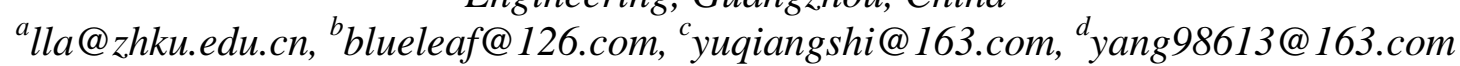

Keywords: Computer network, application-oriented, Teaching reform

Abstract: This paper takes application-oriented undergraduate colleges and universities as the target, and aims at cultivating students' engineering application ability. It analyzes the main problems existing in computer network teaching at present and summarizes some reforms and achievements of ours in the aspects of the theoretical teaching content, teaching team building, construction of online course resources, application of teaching aids, and practical teaching content, etc. The reforms of this paper provide some reference for the reform of computer network courses in similar colleges and universities.

\section{Introduction}

Computer network course is an important professional foundation course for computer-related majors and also an important professional elective course for other engineering majors. In addition, the computer network course is also an introductory course for students to learn network technology and its function is quite important. At present, the Internet is highly developed and has penetrated into every aspect of people's lives. Students can use the network anytime, anywhere, and are very familiar with computer networks. However, the content below the application layer in the network is invisible and intangible when students use the network, and the theoretical concepts in the computer network course teaching are abstract and boring. It is difficult to stimulate students' interest, and their enthusiasm for learning is not high [1-3]. With the continuous development and integration of technologies such as the Internet of Things, cloud computing, big data, mobile Internet, and artificial intelligence, the requirements for network technology are also constantly improving. In general, with the rapid development of information technology, higher requirements are placed on both the instructor and the students who study the network technology. If the teacher teaches well and the students learn well, it will make students have a strong interest in network technology, and thus embark on the road of learning network technology, which is conducive to the professional development of the students. On the contrary, if the teacher does not teach well and the students are difficult to learn well, it will affect the enthusiasm of the students to learn network technology, and run counter to the path of network technology, and go to the direction of learning other technologies. 


\section{The Main Problems in Computer Network Teaching}

The following discusses the main problems in computer network teaching from the aspects of theoretical teaching content, teaching team building, teaching methods and learning methods, etc.

\subsection{Theoretical Teaching Content}

Through the investigation of the existing computer networking textbooks, it is found that the content design of computer networking textbooks is basically organized according to the layered idea, the seven-layer structure based on OSI reference model and the four-layer structure based on TCP/IP reference model respectively. In these textbooks, the layer structure is compromised; organized according to a five-layer structure including the physical layer, data link layer, network layer, transport layer and application layer. The content design of these textbooks adopts bottom-up structure or top-down structure, and the typical representative is [4-5] and [6] respectively. The main knowledge points of computer network course include network architecture and network protocol, WAN physical layer and data link layer, LAN, network layer, transport layer, application layer, network security, etc. Classical computer networking textbooks at home and abroad generally focus on the theoretical knowledge of computer network, while the practical and engineering knowledge is slightly lacking, which are suitable for scientific research students in 985 and 211 universities in China. But for the application-oriented undergraduate colleges and universities, aiming at cultivating students' engineering application ability, most of the students are engaged in engineering technology. It is of great practical significance to design the course content according to the orientation of the application-oriented undergraduate education. In addition, network technology is developing rapidly. In terms of course content design, new technical knowledge should be added in a timely manner to guide students to take the initiative to learn new networkrelated technology, so as to make students learn in line with social needs.

\subsection{Teaching Team Building}

The teaching of computer network courses not only requires the instructors to have profound theoretical knowledge, but also requires them to have strong engineering practice ability. Instructors should not only be familiar with the working principle of computer network and network protocols, but also master the skills of using popular network simulation software and network analysis software, such as Wireshark, eNSP, Packet Tracer, etc. The instructors can use these software to analyze network protocols or simulate to build an actual network topology more intuitively and has relevant network topology drawing, network equipment configuration and debugging ability, network fault location and troubleshooting ability, etc. In addition, the instructors also need to master the latest knowledge and technology of the industry, and be able to provide guiding opinions and suggestions for students to learn new network technology, so that students can learn new network technology by themselves. At present, most of the computer network teachers become teachers directly after graduation from colleges and universities, generally lacking engineering practice. As a result, theories are emphasized in class, but practice is neglected and students' participation rate is low. Students are less active in learning, and the learning effect is not ideal. Therefore, it is necessary to strengthen the training of teachers' engineering practice ability.

\subsection{Teaching Methods and Learning Methods}

In the process of teaching, teachers should pay more attention to the dominant position of students in learning, fully stimulate students' enthusiasm for learning, and cultivate good learning 
habits of students' self-learning and active learning, so that students can take advantage of existing network-related knowledge and technology and actively to analyze, design, and solve the problems related to network system. In addition, only in this way can students' potential be fully stimulated and their technical innovation ability be improved. However, due to the lack of online learning platform or the insufficient resources of online learning platforms, most teachers in colleges and universities currently pay attention to only active teaching and students receive passively when teaching computer network course [7-8]. Students only listen in class, and seldom study independently after class. In addition, most colleges and universities in China are carrying out credit reform, which reduces the time of classroom teaching and greatly increases the credits in practice. Taking the university where the author works as an example, in the talent cultivation program of 2014, the graduation credits of engineering related majors should not exceed 180 credits. But in the talent cultivation program of 2016, the required graduation credits should not be higher than 160 credits, which is nearly 20 credits difference. In the case of the computer network course, the author first started teaching this course in 2008 with a total class time of 72 periods. But the current total class time is 48 periods, there is a difference of 24 periods between them. Therefore, if teachers want to improve the teaching and learning effect of computer network course, they must reform their teaching methods, and students should diversify their learning methods and actively participate in the course learning.

\subsection{Practice Learning Platform}

As mentioned above, due to the abundant theoretical knowledge and complex structure of computer network course, in the traditional teaching mode, teachers often focus on the learning and guidance of theoretical knowledge in classroom teaching [9-10]. However, computer network course is different from pure software or hardware course. It requires the combination of software and hardware knowledge and experimental environment, the close combination of theory and practice, and the complementary combination of theoretical classroom and laboratory experimental innovation. It not only requires students to master network-related principles, but also requires students to have strong engineering practice ability, which is more important for applicationoriented colleges and universities. In order to improve students' engineering practice ability, a good practical learning platform should be provided for them. However, due to the rapid update of network technology and the relatively expensive equipments of network laboratory, it is difficult for colleges and universities to update the equipments in time, which poses a new problem and challenge for students to improve their practical ability. At present, there are many problems such as outdated equipment, isolated network equipment and insufficient resources in the network laboratories of universities. It is necessary to propose effective solutions to make up for this deficiency.

\section{Severall Aspects of Reform}

Aiming at the main problems in the teaching process of computer network course mentioned in the second part, we carried out some reforms in the following aspects.

\subsection{Theoretical Teaching Content Reform}

Theory course is the foundation, is the most important link in the talent training. Different theoretical courses should be designed for different types of students. As mentioned above, the content of computer network theory course in many undergraduate colleges and universities, especially those in 211/985, is mainly designed according to layered ideas and focuses on theories, 
while engineering and practice are insufficient. Especially after the current credit reform in colleges and universities, the practical link is emphasized, and the total class time of courses is much less than before. Therefore, the choice of theoretical teaching content must be made. Based on the investigation of the current typical textbooks, the computer network course teaching team of our university adjusted the theoretical teaching content of the computer network course according to the training objective and orientation of the application-oriented colleges and universities, and published the corresponding textbooks [11-12]. The content of the textbook is designed as follows: Firstly, the basic concept of computer network, network architecture and network protocols are systematically discussed and analyzed. Then, two key technologies in computer network, switching technology and routing technology, are introduced in detail. Finally, the typical application layer protocols are analyzed, and two new network technologies, mobile Internet technology and Internet of things technology, as well as network security technology, are introduced briefly, which provides a guide for readers to learn the new network technology and network security technology. The specific theoretical teaching content is mainly divided into three parts as shown in Figure 1: The first part includes chapter 1 and chapter 2, focusing on the basic knowledge of computer network; The second part includes chapter 3 to chapter 7, focusing on key technologies of computer network; The third part includes chapter 8 and chapter 9, focusing on the further extension of network technology. In addition, in the textbooks, the introduction of new network technologies is emphasized. For example, SDN, NFV, future network, narrowband Internet of things and other related knowledge are introduced.

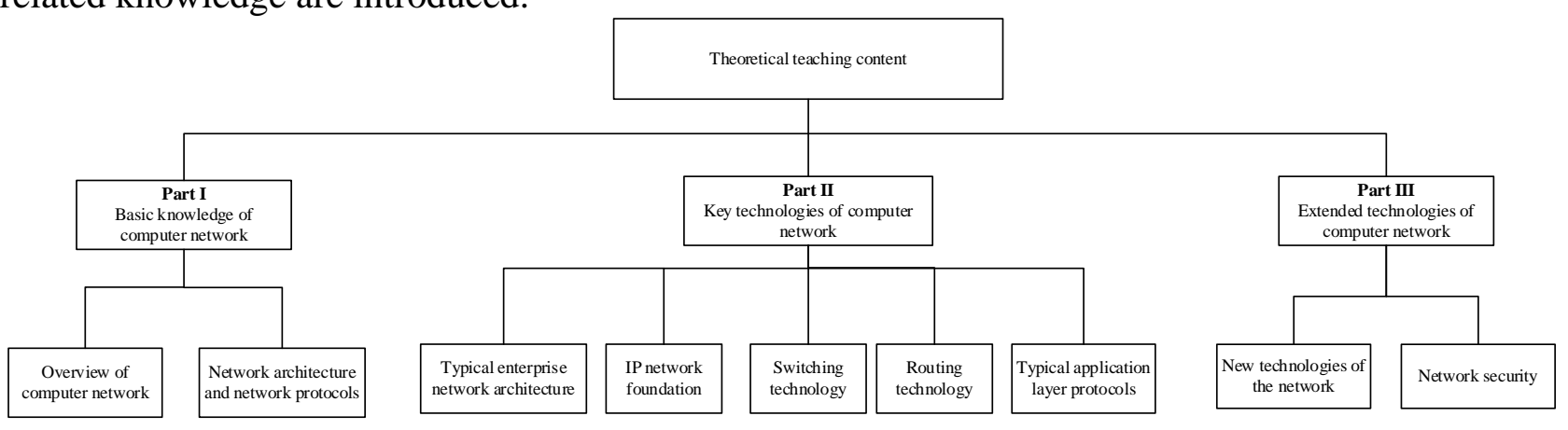

Figure 1 Theoretical teaching content of computer network course.

\subsection{Teacher Training}

To build a "double-qualified" teaching team with solid theoretical knowledge and strong practical ability is of great significance for the improvement of talent cultivation quality. In order to better carry out the teaching of this course, on the one hand, improve the theoretical level and scientific research ability of teachers, and actively choose the teaching team of this course to enter famous universities in China for visiting studies. In the latest three years, we successively sent teachers to South China University of Technology, Jinan University and Sun Yat-sen University for visiting studies; On the other hand, in order to improve the actual IT r\&d ability and engineering quality of the teachers in this course team, we jointly develop the "double-qualified" teacher team training mechanism with the cooperative enterprises. The young teachers of this course team take two vacations every year to work and study in IT enterprises to learn about the latest technologies of network technology-related industries and apply them to teaching. The course team teachers follow the trend of network technology development and keep learning about network technology. In recent years, the course team teachers have obtained several network technology related certificates such as HCNA certificate, HCNA certification lecturer certificate and HCNP certificate. Figure 2 shows two industry certifications obtained by a teacher of the course teaching team. 


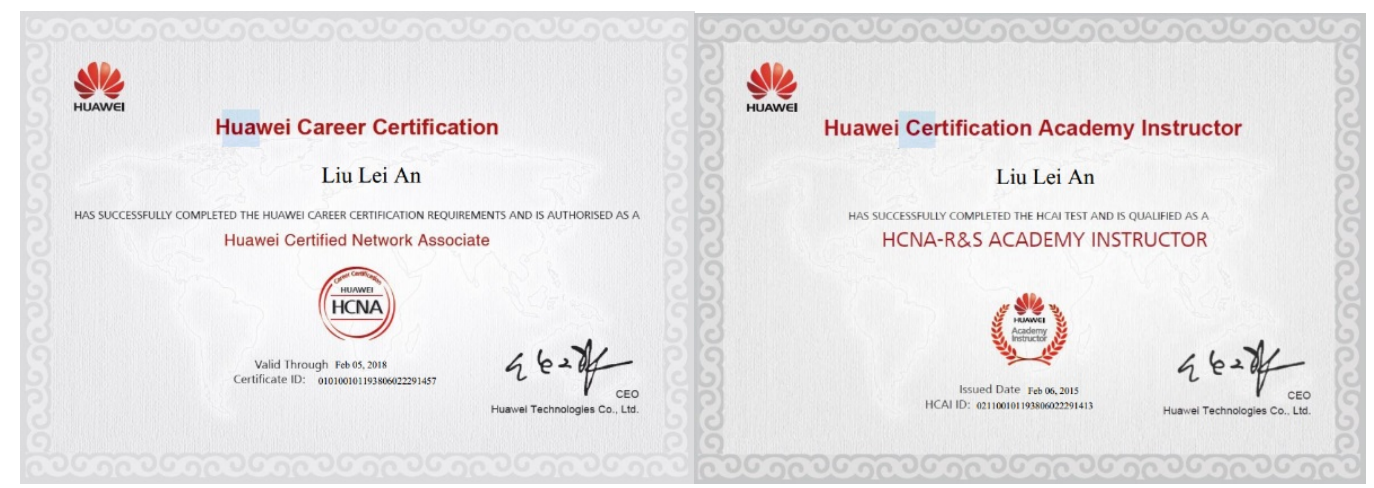

Figure 2 Certifications obtained by a teacher of the computer network course teaching team.

\subsection{Online Course Learning Platform construction}

The online course learning platform is the support. A good online course learning platform can provide students with more flexible learning methods. For teachers, it provides an important support for the reform of teaching methods. In 2013, this course was funded by the university-level quality resource sharing course project, and the course teaching team began to build an online course learning platform. In 2015, the course was funded by the provincial-level quality resource sharing course project. After several years of continuous improvement, a relatively comprehensive online course learning platform has been built, including course introduction, course teaching team, teaching achievements, teaching resources, development resources, homework submission system, communication and interaction modules, etc. This online course learning platform includes all the video resources of the course and covers all the key content of the computer network course. Each video resource is basically controlled within 12 minutes. In addition, students can submit homework and communicate with teachers through this platform and teachers can implement teaching methods such as "flipped classroom", "case teaching method" and "group discussion method", so that students can truly become the subject of learning, which promotes the interaction between teachers and students to the maximum extent, and also enhances students' enthusiasm for learning this course.

\subsection{Several Teaching Aids Application}

In order to make teaching more interesting and increase the interaction with the students, the teacher uses several teaching aids in the teaching process as follows:

- Using the teaching tools such as micro-teaching assistants to call, ask and answer questions, as shown in Figure 3;

- Using eNSP, Packet Tracer, and Wireshark to simulate the network or capture data packets for analysis to enable students to understand network protocols more intuitively;

- Using X-Mind software to create mind maps to enable students to understand the course content from a personal point of view;

- Using microlecture and the online course learning platform to carry out "flipped classroom" to enable students to study independently and increase their participation in the course. 


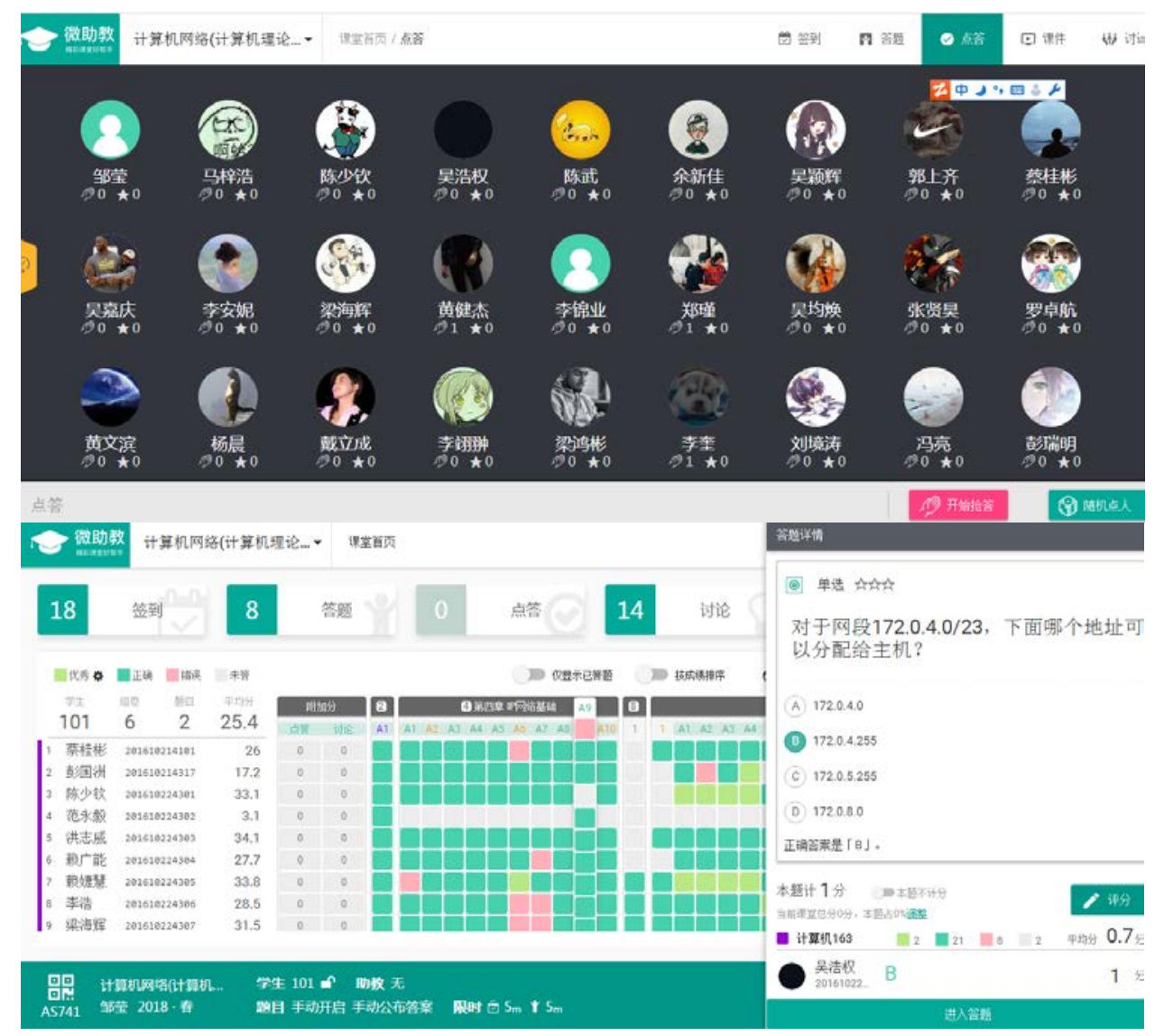

Figure 3 Example of using the micro-teaching assistants in class.

\subsection{Practical Teaching Reform}

Engineering practice ability is particularly important for students in application-oriented undergraduate colleges and universities, and the improvement of this ability must be supported by a good practice platform. The practical teaching of this course mainly includes course experiment and course design. Due to the decrease of class time, it is very important to integrate the course experiment and the course design organically and systematically in order to cultivate students' practical ability. In our 2016 version of the talent training program, there are only 8 periods in the course experiment, and there are three course designs related to this course, "Application of network communication technology", "Network engineering planning and design" and "Comprehensive design of network engineering", a total of 6 weeks. The method of us is to reduce the number of the verification experiments and increase the number of the design and comprehensive experiments. In the course experiment, the teacher puts forward the overall requirements of the experiment according to the teaching syllabus, and students design the experiment by themselves and complete the corresponding tasks, mainly to strengthen students' understanding of basic network-related knowledge points. In the later course design, the three course designs are organically combined and gradually deepened to conduct comprehensive training on students' network technical knowledge. In addition, due to the outdated equipments of the network engineering laboratory of our university, several stable off-campus practice bases established through school-enterprise cooperation provide students with training conditions in the areas of understanding internships, network training, and graduation internships, which further enhances the training conditions. In addition to the above teaching reforms, several measures have been taken to enable students to actively carry out computer network technology learning. For 
example, a network technology group is set up, with senior students as the group leader, computer network teachers and engineers of the school-enterprise cooperation company as the guidance teachers, and one certain network technology will be discussed regularly; A special team of teachers is set up to guide students to carry out the network technology competition and apply for college students' innovation and entrepreneurship projects.

\section{Achievements Obtained}

Through continuous reform and construction in recent years, teachers' ability has been improved, and students' enthusiasm to participate in learning has also been stimulated. In the past three years, the course team teachers won the "Excellent Young Teacher Award" in the school teaching competition, won 1 first prize, 2 second prizes and 3 third prizes of the school's teaching quality excellence awards and won 5 second prizes of education teaching achievement award of the school. More than 20 students have obtained HCNP and HCIE industry certification. The students guided by the course team teachers have obtained 12 excellent theses of network technology and won 32 provincial and above awards in professional technology competition. In particular, Huang Lu, the 131 class of network engineering, won the first prize of the 2016-2017 College ICT Skills Competition of Huawei Information and Network Technology. Figure 4 shows the student competition award certificate and the industry certification obtained by the student.

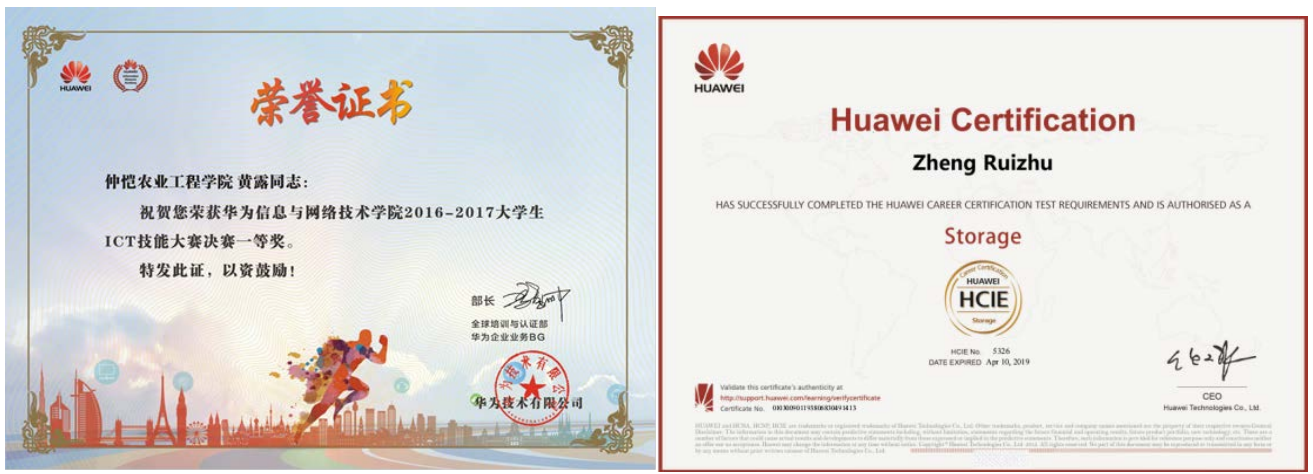

Figure 4 Competition award certificate and the industry certification obtained by the students.

\section{Conclusions}

The teaching reform of computer network course is a continuous topic, and will evolve with the development of the times. Personnel training orientation of different types of university is different and there are also differences in the requirements of students' knowledge, quality and ability. This paper discusses some reforms of computer network course teaching of application-oriented undergraduate colleges and universities. Although some achievements have been made, in the specific implementation process, there are still a lot of work that needs to be further refined, and new solutions should be adopted for the new problems arising from different links.

\section{Acknowledgements}

This work was financially supported by the quality resource sharing course project-“Computer Network” (Official document by Department of education of Guangdong province ([2015] no. 133)), the provincial-level characteristic specialty-"Network Engineering" and the provincial teaching team-“Teaching team of basic core course of computer major" (Official document by Department of education of Guangdong province ([2017]214)), the Science and Technology 
Planning Project of Guangdong Province under Grant (2017A070709012), and 2013 public service research project of Nansha district (2013G001).

\section{References}

[1] Zhang Jianfei, Wang Guoquan, Sun Haitao, etc. Reform of the teaching mode of computer network course in the way of learning and research [J]. Journal of Science of Teachers' College and University, 2018, 38(3): 80-84.

[2] Wang Chunlin, Chen Xiaolin, Qin Haifei. Exploration on the Reform of Computer Network Teaching for Application-oriented Undergraduates [J]. Journal of Chuxiong Normal University, 2018, 33(3): 79-83.

[3] Gao Guang, Wang Ning, Ren Guoheng. Research on the teaching reform of "computer network" course in applied local college [J]. Journal of Zhoukou Normal University, 2017, 34(5): 112-115.

[4] Xie Xiren. Computer Networks (Seventh Edition) [M]. Beijing: Electronic Industry Press, 2017.

[5] Andrew S.Tanenbaum. Computer Networks (Fifth Edition) [M]. Beijing: China Machine Press, 2011.

[6] James F.Kurose,Keith W.Ross. Computer Networking: A Top-down Approach (Seventh Edition) [M]. Beijing: China Machine Press, 2018.

[7] Chen Li, Sun Jieping, Ju Shenggen, etc. Exploration on application of autonomous learning mode in computer network course [J]. Experimental Technology and Management, 2017, 34(8):176-179.

[8] Liu Ling, Xu Jing, Yin Shuxin. Research on the reform of computer network course teaching based on practice and innovation [J]. Contemporary Education Research and Teaching Practice, 2017, (5):159.

[9] Ren Fenghua, Yang Qing, Zhou Ping, etc. Reform and practice of computer network course teaching in electronic information major [J]. Education Teaching Forum, 2016, (21):79-80.

[10] Shao Quanyi, Li Gaojie. Research on the teaching reform of computer network course in applied university [J]. Science \& Technology Ecnony Market, 2018, (1):134-136.

[11] Liu Leian, Zhou Ruqi, Chen Xiaoming. Computer Networks [M]. Beijing: China Railway Press, 2016.

[12] Zou Ying, Zhu Lingli, Cheng Xiaohong. Computer Networks (Second Edition) [M]. Beijing: China Machine Press, 2018. 